\title{
Nilai-Nilai Pendidikan Dalam Surat Luqman
}

\author{
Ahsanul Fuadi dan Eli Susanti \\ Sekolah Menengah Pertama Islam Terpadu (SMP.IT) Abu Bakar Yogyakarta \\ ahsanulfuadi@gmail.com, elisusanti1992@gmail.com
}

\begin{abstract}
The result of this study — library research — showed that the values of Islamic education are contained in the Holy Qur'an surah Luqman. There are at least three basic education, namely aqidah education, syari'ah education and character education. Aqidah education, there are two things: (1) prohibition of associating partners with Allah. Luqman al-Hakim himself had to prioritize monotheism education (tauhid) to his children, (2) believe in the place of hereafter. Luqman ordered his children to believe the reward of all his deeds. Especially retaliation for our gratitude to Him for every blessing and our sense of respect for both parents. Syari'ah Education, there are two things, namely a command set up prayer and amar ma'rūf nahy munkar. Character education, which is the command to ingratitude towards Allah SWT. For all the blessings and grace of God, we should be grateful to Him.
\end{abstract}

Keywords: Luqman al-Hakim; values education,

Abstrak: Artikel ini merupakan penelitian kepustakaan. Penelitian menunjukkan bahwa Pendidikan Islam termuat dalam al-Qur'an Surat Lukman. Setidaknya ada tiga tingkatan yaitu pendidikan aqidah, pendidikan syari'ah, dan pendidikan karakter. Pendidikan aqidah meliputi dua hal: (1) larangan mensekutukan Allah. Lukman Hakim memprioritaskan pendidikan tauhid kepada anak-anak; (2)mempercayai hari akhir. Lukman Hakim mengajarkan kepada anak-anaknya untuk mempercayai balasan atas perbuatan yang dilakukan di dunia. Pendidikan syariah meliputi dua hal, yaitu mendirikan sholat dan amar ma'rüf naby munkar. Pendidikan karakter meliputi perintah untuk bersyukur kepada Allah atas semua karunia-Nya.

Keywords: Luqman al-Hakim; Nilai-nilai pendidikan.

\section{Pendahuluan}

Nilai diarti denotatifnya dapat dimaknai sebagai harga. Namun ketika nilai dihubungkan dengan suatu objek atau sudut pandang tertentu, harga yang terkandung di dalamnya memiliki pemaknaan yang bermacam-macam. Selanjutnya kaitan dengan nilai pendidikan, maka, mengandung arti konsep pendidikan menjadi bahan utama dalam pertimbangan nilai. Dengan demikian, nilai pendidikan yang akan dikaji dalam tulisan ini adalah sesuatu yang berharga yang memiliki kaitan dan mendukung pemikiran dan pelaksanaan pendidikan khususnya dalam surah Luqman yakni: 


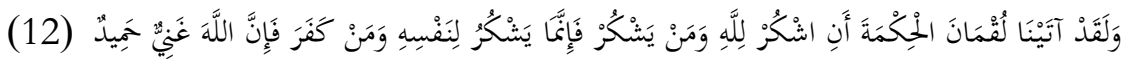
Dan sesunggubnya telah Kami berikan bikmah kepada Lukman, yaitu: "Bersyukurlah kepada Allah. Dan barang siapa yang bersyukur (kepada Allab), maka sesunggubnya ia bersynkur untuk dirinya sendiri; dan barang siapa yang tidak. bersyukur, maka sesunggubnya Allah Maha Kaya lagi Maha Terpuji". (Q.S. Luqman:12)

Al-qur'an adalah kitab suci terbesar yang tidak ada tandingannya. Di dalamnya memuat segala macam petuah/nasehat, ibroh, nilai pendidikan dan lain sebagainya yang tidak mungkin dibuat oleh seseorang sehebat, dan sepandai apapun seseorang tersebut. Sebagai kitab rujukuan bagi dunia pendidikan, AlQur'an memuat nilai-nilai pendidikan yang luhur yang dapat diterapkan dalam dunia pendidikan sepanjang masa.

Salah satu surat yang memuat banyak tentang pendidikan adalah surat Luqman $^{1}$ dan dalam kaitannya dengan dunia pendidikan akan menjadi sesuatu yang penting dan menarik apabila kita menggali nilai-nilai pendidikan yang ada dalam surat Luqman. Dalam kaitan pendidikan tersebut penulis akan memaparkan nilai-nilai pendidikan yang tertulis dalam surat luqman ayat 12-19, yang merupakan inti dari sebuah nilai pendidikan karena ayat tersebut berisi tentang nasehat-nasehat Luqman pada anak-anaknya. Yang apabila digali ungkapan nasehat di dalamnya, maka akan terungkap nilai-nilai pendidikan yang luas, karena Luqman adalah orang yang dipilih Allah yang telah diberi keluasan ilmu dan diberi anugerah untuk melaksanakan ilmu yang dimilikinya.

Kemampuan yang ada pada Luqman selanjutnya Allah menyebutnya dengan telah memberikah hikmah ${ }^{2}$ kepadanya yang berarti bahwa mengetahui yang paling utama dari segala sesuatu, baik pengetahuan maupun perbuatan

${ }^{1}$ Surat Luqman adalah surat yang ke 31 dalam Al-Qur'an yang terdiri dari 34 ayat. Termasuk golongan surat Makiyyah, karena diturunkan di Mekah sebelum Hijrah. Surat ini dinamakan Luqman yang diambil dari ayat 12.

${ }^{2}$ Para ulama memaknai bikmah sebagai sesuatu yang bila digunakan/diperhatikan akan menghalangi terjadinya mudarat atau kesulitan yang lebih besar dan atau mendatangkan kemaslahatan dan kemudahan yang lebih besar. Makna ini ditarik dari kata bakamah yang berarti kendali, karena kendali menghalangi hewan/kendaraan mengarah ke arah yang tidak diinginkan atau menjadi liar. Memilih perbuatan terbaik yang terbaik dan sesuai adalah perwujudan dari hikmah, memilih yang terbaik dari dua hal yang buruk pun, dinamai hikmah dan pelakunya dinamai bakim (bijaksana) 
karena ia adalah ilmu amaliah dan amal ilmiah, ia adalah ilmu yang didukung oleh amal dan amal yang tepat dan didukung oleh ilmu.

\section{Pembahasan}

\section{1. (Sekelumit kisah tentang Luqman al-Hakim) اللمحة عن لقمن الحكيم}

Luqman yang dipilih Alloh yang namanya diabadikan dalam Al-Qur'an untuk memaparkan dengan lisannya tentang perkara tauhid, perkara akhirat dan perkaraperkara yang lain yang sarat dengan nilai-nilai pendidikan berbeda-beda dan bermacammacam riwayat tentang dirinya. Ada yang mengatakan bahwa dia adalah seorang nabi. Dan ada pula yang mengatakan bahwa dia hanyalah seorang hamba yang saleh bukan seorang nabi, dan kebanyakan ulama mendukung pendapat ini. ${ }^{3}$

M. Quraish Shihab dalam tafsirnya menuliskan bahwa orang Arab mengenal dua tokoh yang bernama Luqman, pertama Luqman Ibn 'Ad, tokoh ini mereka agungkan karena wibawa, kepemimpinan, ilmu, kefasihan dan kepandaianya. Ia kerap dijadikan sebagai permisalan dan perumpamaan. Tokoh kedua, adalah Luqman al-Hakim yang terkenal dengan kata-kata bijak dan perumpamaan-perumpamaannya. Agaknya dialah yang dimaksud dalam surah ini.

Mengenai keberadaan kewarganegaraan sosok Luqman al-Hakim inipun banyak pendapat mengenai siapakah dia. Ada yang mengatakan bahwa ia berasal dari Nuba, dari dari penduduk Ailah. Ada juga yang mengatakan bahwa dia berasal dari Etiopia, ada pula yang mengatakan bahwa dia adalah seorang Ibrani. ${ }^{4}$ Menurut hemat penulis, siapaun Luqman al-Hakim, adalah tidak perlu diperdebatkan keberadannya, yang terpenting adalah bahwa menggali dan menyelami pelajaran-pelajaran yang dapat di ambil melalui nasehat-nasehatnya merupakan sesuatu yang bijaksana, berdasarkan pesan "dengarkanlah apa yang disampaikan, jangan melihat siapa yang menyampaikan"

${ }^{3}$ Sayyid Quthb, Tafsir Fi Zhilalil Qur'an, Jakarta, Gema Insani. 2004. jilid 17, Hlm. 261

${ }^{4}$ M. Quraish Shihab. Tafsir Al-Mishbah, Pesan, Kesan dan Keserasian Al-Qur'an, Jakarta, Lentera hati, 2006. Volume 11. Hlm. 125-126 


\section{Nilai-Nilai pendidikan dalam Surat Luqman dan Implementasinya dalam dunia pendidikan}

Setelah mengetahui sosok Luqman al-Hakim, berikut kami paparkan pelajaran/pesan-pesan yang disampaikan oleh Luqman Al-Hakim yang tertuang dalam Q.S. Luqman ayat 13-19.

\section{Pelajaran pertama tentang Ketauhidan}

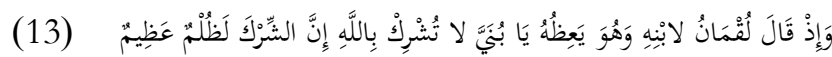

Dan (ingatlah) ketika Lukman berkata kepada anaknya, di waktu ia memberi pelajaran kepadanya: "Hai anakku, janganlah kamu mempersekutukan (Allah) sesunggubnya mempersekutukan (Allah) adalah benar-benar kelaliman yang besar".

Kata بَنيَّ adalah patron yang menggambarkan kemungilan. Asalnya adalah ابنىى dari kata ابن yakni anak lelaki. Pemungilan tersebut mengisaratkan kasih sayang. Dari sini kita dapat berkata bahwa ayat di atas memberi isyarat bahwa mendidik hendaknya didasari oleh rasa kasih sayang terhadap peserta didik. ${ }^{5}$ Selain itu, dalam memanggil anak-anak hendaknya menggunakan panggilan yang mencerminkan kelembutan dan kasih sayang, karena panggilan kepada anak didik dengan panggilan "anakku” tentunya akan menjadikan anak didik merasa nyaman. Rosulullah sendiri tidak melarang memanggil anak orang lain dengan sebutan anakku. ${ }^{6}$

Pelajaran pertama yang disampaikan adalah tentang ketauhidan, Luqman memulai nasehatnya dengan menekankan perlunya menghindari syirik/mempersekutukan Alloh. Larangan ini sekaligus menandung pengajaran tentang wujud dan keesaan Tuhan. Bahwa redaksi pesannya berbentuk larangan, jangan mempersekutukan Alloh untuk menekan perlunya meninggalkan sesuatu yang buruk

${ }^{5}$ Lihat tafsir Al-Mishbah, Volume 11, Hlm. 127

${ }^{6}$ Musthafa al-'Adawi. Fikih Pendidikan Anak, Membentuk Kesaleban Anak Sejak Dini. Jakarta. Qisthi Press. 2007. Hlm. 48 
sebelum melaksanakan yang baik. Dalam kaitannya dengan dunia pendidikan hendaknya pesan/nasehat ini dihubungkan dengan kaidah ushul "At-takhliyah muqoddamun 'ala attahliyah" (menyingkirkan keburukan lebih utama daripada manyandang perhiasan) atau "dar'u al-mafasid muqoddamun 'ala jalbi al-mashalib" (meninggalkan sesuatu yang merusak lebih utama daripada melaksanakan sesuatu yang baik).

Mengapa pelajaran yang diajarkan pertama adalah ketauhidan?. Dalam struktur ajaran Islam, Taubid merupakan hal yang amat fundamental dan mendasari segala aspek kehidupan para penganutnya, tak terkecuali aspek pendidikan. ${ }^{7}$ Dalam kaitan ini seluruh pakar sependapat bahwa dasar pendidikan (Islam) adalah tauhid. Melalui dasar ini dapat dirumuskan hal-hal sebagai berikut :

Pertama, kesatuan kehidupan. Bagi manusia ini berarti bahwa kehidupan duniawi menyatu dengan kehidupan ukhrawinya. Sukses atau kegagalan ukhrawi ditentukan oleh amal dunianya.

Kedua, kesatuan ilmu. Tidak ada pemisahan antara ilmu-ilmu agama dan ilmuilmu umum, karena semuanya bersumber dari satu sumber, yaitu Allah SWT.

Ketiga, kesatuan iman dan rasio. Karena masing-masing dibutuhkan dan masingmasing mempunyai wilayahnya sehingga harus saling melengkapi.

Keempat, kesatuan agama. Agama yang dibawa oleh para nabi kesemuanya bersumber dari Allah SWT, prinsip-prinsip pokoknya menyangkut aqidah, syari'ah dan akhlak tetap sama dari zaman dahulu sampai sekarang.

Kelima, kesatuan kepribadian manusia. Mereka semua diciptakan dari tanah dan Ruh Ilahi.

Keenam, kesatuan individu dan masyarakat. Masing-masing harus saling menunjang. ${ }^{8}$

${ }^{7}$ Sulistyorini. Manajemen Pendidikan Islam, Konsep, Strategi dan Aplikasi, Yogyakarta, Teras. 2009. Hlm. 23

${ }^{8}$ M. Quraish Shihab. Wawasan Al-Qur'an, Tafsir Maudlu'i atas Pelbagai Persoalan umat, Bandung, Mizan, 1996. Hlm. 382-383 


\section{Pelajaran kedua tentang berbakti kepada kedua orang tua}

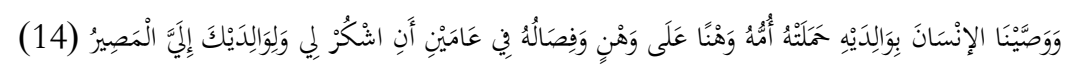

"Dan Kami perintabkan kepada manusia (berbuat baik), kepada dua orang ibu-bapaknya; ibunya telah mengandungnya dalam keadaan lemah yang bertambah-tambah, dan menyapibnya dalam dua tahun. Bersyukurlah kepada-Ku dan kepada dua orang ibu bapakmu, banya kepadaKulab kembalimu."

Pesan/pelajaran kedua dalam surat ini seperti dinasehatkan Luqman adalah kewajiban manusia untuk berbakti kepada kedua orang tua karena jasa dan pengorbanan yang tidak ternilai yang diberikan oleh orang tua kepada anaknya. Wasiat bagi anak untuk berbakti kepada kedua orang tuanya muncul berulang-ulang dalam Al-Qur'an. Sesungguhnya kedua orang tua pasti mengeluarkan segalanya bagi anak-anaknya baik apapun yang mereka miliki dalam jasadnya, dalam umurnya maupun segala yang mereka miliki dengan penuh kasih sayang. ${ }^{9}$

Pengorbanan orang tua yang demikian besar, memberikan pelajaran tentang keikhlasan dalam berbuat sesuatu, yakni mengerjakan segala sesuatau tanpa mengharapkan imbalan atas perbuatan baik yang telah diperbuat, di samping sikap bakti yang ditunjukkan oleh seorang anak kepada kedua orang tuanya mengandung makna balas budi atau rasa terimakasih seorang anak, untuk selalu bersyukur kepada Allah dan berterima kasih kepada kedua orang tuanya.

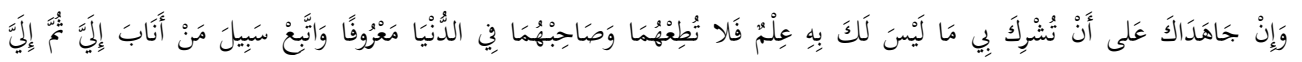

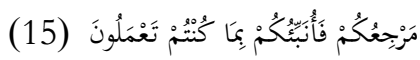

"Dan jika keduanya memaksamu untuk mempersekutukan dengan Aku sesuatu yang tidak ada pengetahuanmu tentang itu, maka janganlah kamu mengikuti keduanya, dan pergaulilah

\footnotetext{
${ }^{9}$ Lihat Tafsir Fi dzilali Qur'an. Jilid 17, Hlm. 263
} 
keduanya di dunia dengan baik, dan ikutilah jalan orang yang kembali kepada-Ku, kemudian hanya kepada-Kulah kembalimu, maka Ku-beritakan kepadamu apa yang telah kamu kerjakan.”

Dalam kaitanya dengan berbakti kepada kedua orang tua, ada beberapa hal yang merupakan pengecualian menaati kedua orang tua, sekaligus menggarisbawahi wasiat Luqman kepada anaknya tentang keharusan meninggalkan kemusyrikan dalam bentuk serta kapan dan di manapun. Ayat di atas menyatakan : Dan jikea keduanya - apalagi kalau hanya salah satunya-, lebih-lebih kalau orang lain bersungguh-sungguh memaksamu mempersekutukan Aku dengan sesuatu yang tidak ada pengetahuanmu tentang itu, apalagi setelah Aku dan rasul-rasul menjelaskan kebatilan mempersekutukan Allah, dan setelah engkau mengetahui bila menggunakan nalarmu, maka janganlah engkan mematubinya keduanya. Namun demikian jangan memutuskan hubungan dengannya atau tidak menghormatinya. Tetapi tetaplah berbakti kepada keduanya selama tidak bertentangan dengan ajaran agamamu, dan pergaulilah keduanya di dunia yakni selama mereka hidup dan dalam urusan keduniaan - bukan akidah - dengan pergaulan yang baik, tetapi jangan sampai hal ini mengorbankan prinsip agamamu. ${ }^{10}$

\section{Pelajaran ketiga tentang "Etika Otonom"11}

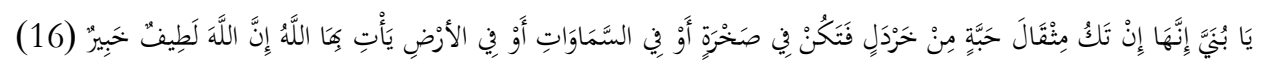

"(Lukman berkata): "Hai anakku, sesunggubnya jika ada (sesuatu perbuatan) seberat biji sawi, dan berada dalam batu atau di langit atau di dalam bumi, niscaya Allab akan mendatangkannya (membalasinya). Sesungguhnya Allab Maha Halus lagi Maha Mengetabui."

Ayat di atas melanjutkan wasiat Luqman kepada anaknya. Kali ini tentang kedalaman ilmu Alloh swt., yang diisyaratkan dalam pesan Luqman "Wahai anak.ku, sesunggubnya jikea ada sesuatu perbuatan baik atau buruk walaupun seberat biji sawi dan berada pada tempat yang paling tersembunyi, misalnya dalam batu karang sekecil,

\footnotetext{
${ }^{10}$ Lihat Tafsir Al-Mishbah. Volume 11, Hlm. 131-132

${ }^{11}$ Etika otonom adalah suatu perilaku atau sikap di mana seseorang selalu berbuat baik,
} karena ia merasa ada yang mengawasi, yaitu Tuhan yang maha kuasa 
sesempit dan sekokoh apapun batu itu, atau di langit yang demikian luas dan tinggi, atau dalam perut bumi yang sedemikian dalam di manapun keberadaannya niscaya Allah akan mendatangkannya lalu memperhitungkan dan memberinya balasan. Sesunggubnya Allah maha halus menjangkau segala sesuatu baginya adalah sesuatu yang amat mudah karena ia maha mengetahui segala sesuatu sehingga tak ada sesuatupun yang luput dari-Nya.

Ayat ini memberikan pelajaran motivasi bagi anak untuk giat beramal kebajikan meskipun sebesar dzarah (kecil sekali) karena Allah Maha tahu dan pasti akan membalasnya. ${ }^{12}$ Pelajaran yang dapat diambil adalah bahwa siapapun orangnya, sekecil apapun kebaikan dan keburukan yang dilakukannya niscaya akan kembali pada dirinya sendiri, karena Allah maha tahu, maha teliti dan maha adil, maka barang siapa menanam kebaikan, maka ia akan menuai pahala yang akan menjadikan ia bahagia dalam hidupnya serta siapa saja yang menanam keburukan tentu ia akan menuai dosa yang akan menjadikan ia sengsara dalam hidupnya. Reward dan punishment's adalah sesuatu yang penting dilakukan dalam dunia pendidikan untuk memberikan penghargaan bagi anak didik yang berprestasi dan memberikan pembinaan bagi anak didik yang melanggar aturan.

\section{Pelajaran keempat tentang ubudiyah dan amal saleh}

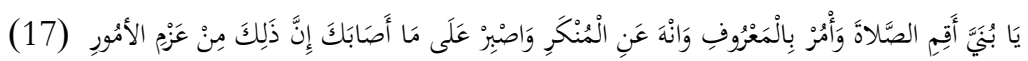

"Hai anakku, dirikanlah salat dan surublah (manusia) mengerjakan yang baik dan cegablah (mereka) dari perbuatan yang mungkar dan bersabarlah terhadap apa yang menimpa kamu. Sesunggubnya yang demikian itu termasuk hal-hal yang diwajibkan (oleh Allah)."

12 http://kbi.gemari.or.id/beritadetail.php?id=4441 penulis Karnita S.Pd POSTING, 3 November 2009

13 Dalam menjalankan Reward dan Punishment hendaknya seorang pendidik atau lembaga pendidikan dengan menyesuaikan kondisi fisik dan psikis siswa, serta latar belakang kehidupan dan lingkungannya. 
Setelah merasa anak-anaknya sudah paham dengan materi ketauhidan dan kesempurnaan Alloh, selanjutnya diberikanlah pelajaran-pelajaran mengenai ibadah dan amal saleh. Nasihat luqman selanjutnya adalah menyangkut hal-hal yang berkaitan dengan amal-amal saleh yang puncaknya adalah shaalat, serta amal-amal kebajikan yang tercermin dalam amar ma'ruf nahi munkar, juga nasihat berupa perisai membentengi seseorang dari kegagalan yaitu sabar dan tabah. Menyuruh hal-hal yang ma'ruf, mengandung pesan untuk mengerjakannya, karena tidaklah wajar menyuruh sebelum diri sendiri mengerjakannya. Demikian juga melarang kemunkaran, menuntut agar yang melarang terlebih dahulu mencegah dirinya, karena tidaklah lucu apabila orang yang memerintah tidak melaksanakan, orang yang melarang malah melakukan, seperti ancaman Alloh tentang dosa orang yang hanya bisa berkata tanpa melakukan sesuatu yang diucapkannya :

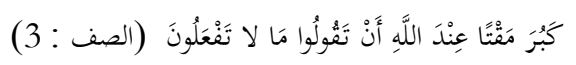

"Amat besar kebencian di sisi Allah babwa kamu mengatakan apa-apa yang tiada kamu kerjakan."

Itu agaknya yang menjadi sebab mengapa Luqman tidak memerintahkan anaknya melaksanakan ma'ruf menjauhi munkar, tetapi memerintahkan anaknya, menyuruh dan mencegah. Di sisi lain membiasakan anak melaksanakan tuntunan ini menimbulkan dirinya mempunyai jiwa kepemimpinan serta kepedulian sosial. ${ }^{14}$ Dalam melaksanakan kebaikan ubudiyah dan amal saleh amar ma'ruf nahi munkar, tentunya banyak kendala, rintangan dan cobaan, maka dalam menghadapinya diperlukan kesabaran, karena kesabaran termasuk hal-hal yang diutamakan.

\section{Pelajaran kelima tentang Akhlak}

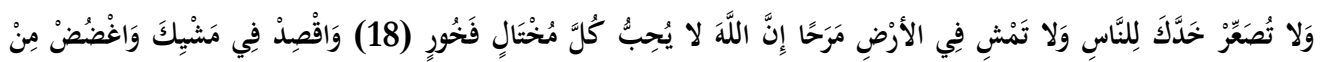

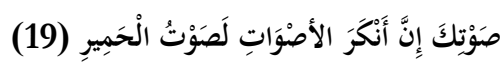


"Dan janganlah kamu memalingkan mukamu dari manusia (karena sombong) dan janganlah kamu berjalan di muka bumi dengan angkuh. Sesunggubnya Allah tidak menyukai orangorang yang sombong lagi membanggakan diri." Dan sederhanalah kamu dalam berjalan dan lunakekanlah suaramu. Sesunggubnya seburuk-buruk suara ialah suara keledai."

Nasihat Luqman selanjutnya berkaitan dengan akhlak dan sopan santun berinteraksi dengan sesama manusia. Materi pelajaran Tauhid atau Akidah, beliau selingi dengan materi pelajaran akhlak, yang mengisyaratkan bahwa ajaran akidah dan akhlak merupakan satu kesatuan ilmu yang tidak dapat dipisahkan. Selain itu, penyampaian materi lain (akhlak) setelah penyampaian materi akidah juga dimaksudkan agar peserta didik tidak jenuh dengan satu materi. Dalam kaitannya dengan hal ini, penting bagi seorang pendidik agar selalu melakukan perubahan-perubahan (pengembangan diri) dalam pola pengajarannya, sehingga metode pembelajaran yang dilakukannya selalu menarik dan menyenangkan tanpa mengurangi kaidah-kaidah pokok dalam pembelajaran sesuai dengan prinsip model pembelajaran paikem, ${ }^{15}$ yang akan membuat siswa aktif, kreatif dalam kegiatan belajar.

Nasehat/pelajaran Luqman dalam ayat tersebut adalah tentang larangan berlaku sombong. Semua kesombongan wajib dijauhkan dan dihindari karena dapat menimbulkan penyakit hati yang merusak diri sendiri dan orang lain, ${ }^{16}$ juga karena kesombongan itu pulalah seseorang akan terhalang menikmati indahnya sorga, sabda Nabi : "tidak akan masuk sorga orang yang mempunyai sifat kesombongan walaupun sebesar biji dzarrab”. Dia berkata : wahai anakku, janganlah engkau berkeras memalingkan pipimu ${ }^{17}$

${ }^{15}$ Model pembelajaran Paikem adalah model pembelajaran yang memuat prinsipprinsip pembelajaran yang aktif, inovatif, kreatif, efektif dan menyenangkan. Di dalam pembelajaran tersebut ada beragam cara pembelajaran agar peserta didik dapat mengikuti aktifitas belajar tanpa merasa jenuh dan bosan.

${ }^{16}$ M. Yatimin Abdullah. Studi Akhlak dalam Perspektif Al-Qur'an. Jakarta. Sinar Grafika Offset. 2007. Hlm. 67

${ }^{17}$ Dalam tafsir Al-Mishbah, kata memalingkan pipi dibahasakan dalam al-qur'an dengan istilah تُصَعِّر (tusha'ir) yang terambil dari kata آلصَّعْرُ (Ash-sha'ru) yaitu penyakit yang menimpa unta dan menjadikan lehernya keseleo, sehingga ia memaksakan dia dan berupaya keras agar berpaling sehingga tekanan tidak tertuju kepada syaraf lehernya yang mengakibatkan rasa sakit. Dari kata 
yakni mukamu dari manusia, siapapun dia, karena didorong oleh perasaan untuk menghina atau berlaku sombong. Tetapi tampillah kepada setiap orang dengan wajah berseri penuh rendah hati. Dan bila engkau melangkah, janganlah berjalan di muka bumi ini dengan angkuh, tetapi berjalanlah dengan lemah lembut penuh wibawa. Sesungguhnya Allah tidak menyukai yakni tidak melimpahkan anugerah kasih sayangNya kepada orang-orang yang sombong lagi membanggakan diri. Dan bersikap sederhanalah dalam berjalanmu, yakni jangan membusungkan dada dan jangan pula merunduk bagaikan orang sakit. Jangan berlari tergesa-gesa dan jangan juga sangat perlahan menghabiskan waktu. Dan lunakkanlah suaramu sehingga tidak terdengan kasar bagaikan teriakan keledai. Sesungguhnya seburuk-buruk suara adalah suara keledai karena awalnya siulan yang tidak menarik dan akhirnya tarikan nafas yang buruk. ${ }^{18}$

\section{Kesimpulan}

Sungguh sangat luas dan bijak nasehat-nasehat Luqman al-Hakim, alangkah indahnya jika pelajaran-pelajaran yang disampaikan oleh Luqman diterapkan dalam model pembelajaran pendidikan kita. Secara garis besar, pesan-pesan Luqman kepada puteranya mencakup tiga aspek pedagogis: aspek tauhid, syariat/ibadah, dan akhlak, tiga unsur ajaran al-Qur'an. Pesan-pesan itu perlu dijabarkan dalam proses pembelajaran di semua mata pelajaran.

Pendidikan Nasional kita juga sebenarnya bermisi menghasilkan peserta didik yang beriman, bertaqwa, berakhlak mulia, dan cerdas. Mata pelajaran agama, kewarganegaraan, bahasa Indonesia, dan pelajaran lainnya sama-sama menanamkan kebajikan yang bermuara pada tujuan membentuk pribadi dan akhlak mulia. Namun, penerapannya masih belum optimal.

Patut dipertanyakan, mengapa keimanan dan ketaqwaan anak didik kita demikian rendah? Rendahnya keimanan dan ketaqwaan tersebut berbanding lurus dengan

inilah ayat di atas menggambarkan upaya keras dari seseorang untuk bersikap angkuh/sombong dan menghina orang lain. Memang sering kali penghinaan tercermin pada keengganan melihat siapa yang dihina.

${ }^{18}$ Lihat tafsir Al-Mishbah. Hlm. 139 
dekadensi moral yang kini semakin menggejala. Dewasa ini, banyak terjadi kasus yang mencerminkan deviasi (penyimpangan) perilaku anak didik yang amoral. Berbagai kejahatan dilakukan terhadap teman sendiri. Begitu juga, sikap tidak hormat terhadap orang tua sudah menjadi tontonan yang biasa. Belum lagi bila melihat pergaulan para remaja dan anak-anak usia sekolah yang semakin sulit dikontrol.

Kita tidak menghendaki pendidikan hanya menjadi tempat mentransfer ilmu saja. Pendidikan harus meliputi transformasi pengetahuan, sekaligus juga mengedepankan pendidikan moral. Untuk mencapai tujuan manusia beriman, bertakwa, dan berakhlakul karimah, seyogianya kepala sekolah dan para guru melakukan berbagai ikhtiar agar nilai-nilai keagamaan, kebahasaan, kewarganegaraan, kesenian, dan yang lainnya benar-benar terinternalisasi.

Orang tua juga mempunyai tanggung jawab yang besar dalam menginternalisasikan nilai-nilai tersebut. Mereka seyogyanya membimbing siswa melalui ucapan, pikiran, dan tindakan. Penanaman nilai dilakukan dengan cara mencairkan terlebih dahulu hambatan-hambatan psikologis dalam hubungan mereka dengan siswa. Pencapaian nilai-nilai keimanan, ketakwaan, dan akhlakul karimah harus direduksi (disederhanakan) ke dalam tema-tema sejumlah program dan peristiwa pendidikan pada situasi praktis. Semoga dengan upaya tersebut, pendidikan dapat mengartikulasikan dan menginternalisasikan pesan-pesan pedagogis. Mari kita belajar dari Luqman! 


\section{Daftar Pustaka}

Abdullah, Yatimin M. 2007. Studi Akblak dalam Perspektif Al-Qur'an. Jakarta. Sinar Grafika Offset.

Al-'Adawi, Musthafa. 2007. Fikib Pendidikan Anak, Membentuk Kesalehan Anak Sejak Dini. Jakarta. Qisthi Press.

Sulistyorini. 2009. Manajemen Pendidikan Islam, Konsep, Strategi dan Aplikasi. Yogyakarta. Teras

Quraih, Shihab M. 2006. Tafsir Al-Mishbah, Pesan, Kesan dan Keserasian Al-Qur'an. Jakarta. Lentera Hati.

Quraish, Shihab M. 1996. Wawasan Al-Qur'an, Tafsir Maudlu'i atas Pelbagai Persoalan umat. Bandung. Mizan

Quthb, Sayyid. 2004. Tafsir Fi Zhilalil Qur'an. Jakarta. Gema Insani.

Karnita, http://kbi.gemari.or.id/beritadetail.php?id=4441 posting, 3 November 2009 
138 | BELAJEA : Jurnal Pendidikan Islam, Vol. 2, No. 02, 2017 